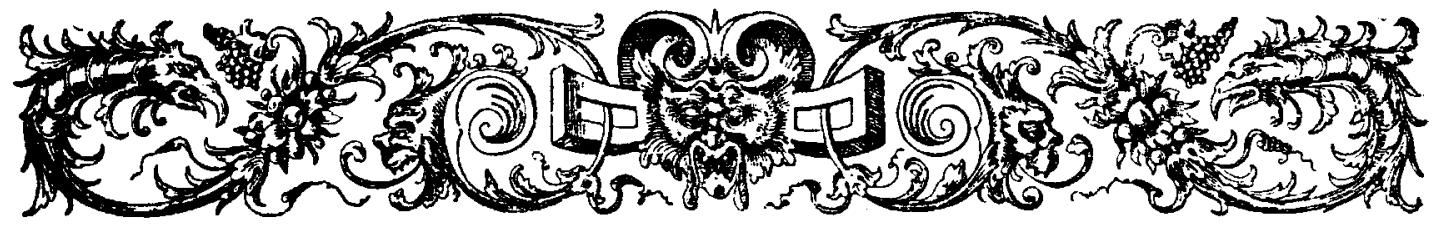

\title{
HET EINDE VAN PASCHIER LAMERTIJN
}

DOOR

JHR. DR. J. SIX.

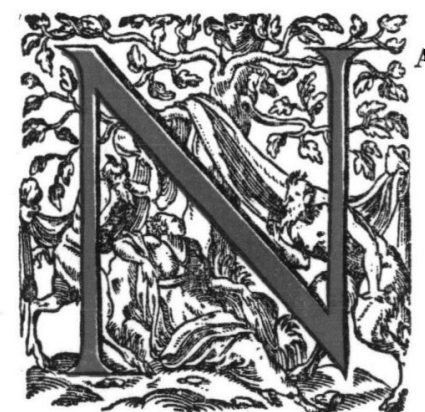

AUWELIJKS was mijn onderzoek over PASCHIER LAMERTIJN in dit Tijdschrift XXXI, 19I3, blz. 85 verschenen of ik ontving van Mejuffrouw Elas Mygdal te Kopenhagen een overdruk van haar rijk verlucht en zeer doorwerkt opstel uit het Tidsskrift for Industri I 9 I 3, getiteld „Af dækketøjets historie" waarin, naast reeds bekende patronen ook nieuwe, als de wonderverhalen van DANIËL met Dagon en den draak of als een eenvoudige jacht, uit I 594 met de wapens van $O$ (TTO) $B$ (ANNER) en I(NGEBORG) $S$ (KEEL) en uit 1596 met de wapens van $B$. R(OSEN)S(PARRE), P(REDBJøRN) G(YLDEN)S(TIERN) en M(ETTE) $\mathrm{H}(\mathrm{ARDEN}) \mathrm{B}(\mathrm{ERG})$ werden afgebeeld.

Onder die allen trokken het meest mijn aandacht Fig. I9 en 20, klaarblijkelijk patronen van PASCHIER LAMERTIJN, al droegen zij de letters ingeweven van K(ARL) T(HIESEN), bestuurder en opzichter van de koninklijke zijdeweverij te Kopenhagen en kwam de naam van PASCHIER niet voor onder de verschillende wevers, volgens oorspronkelijke bescheiden vermeld.

Toch kon er geen twijfel zijn of "banquet op tafel” in het midden met aan de korte zijde afhangende wapens, in de breede randen, ,jachten en schepen en duynen en anders" gaf ons zijn patronen weer. De wapens waren wel niet die van Nassau, maar kwamen geheel overeen met die van CHRISTIAAN VAN Oud.Holland 1915. 
DENEMARKEN, die ik hem reeds vroeger toeschrijven kon; alleen waren de schilden eenigzins anders gerangschikt en had in de $C$ van CHRISTIAAN IV een 4 het monogram van zijn gemalin vervangen, nu hij sedert I6I 2 weduwnaar was geworden. Want deze weefsels waren van $162 \mathrm{I}$ en $\mathrm{I} 622$. Het beste bewijs dat wij met geen vrije navolging te doen hadden, leverde zeker de eene rand van het linnen tafellaken te Rosenborg, Fig. 19, hier P1. I, waar wij het hollandsche strand vinden met de zeilwagens die Simon Stevijn voor Prins Maurits bouwde. De jacht in de duinen van den anderen rand moge voor menigeen denkbaar wezen, het zeilwagenpatroon kon vocr niemand anders dan voor MAURITS ontworpen zijn, waarschijnlijk tegelijk met zijn servetten van I601, al vonden wij zulk tafelgoed het eerst vermeld in den aankoop van I6II voor de PRINSES VAN ORANJE.

Dit tafellaken te Rosenborg, lang 6 el $\mathrm{I}^{\prime \prime}{ }^{1}$ ) in den hoek gemerkt B $61 / 2$ is blijkbaar, volgens eigenhandige kwijting van den koning, nog in het Deensche rijksarchief berustende, één van de vier doeken van damast geleverd den 8 Juni

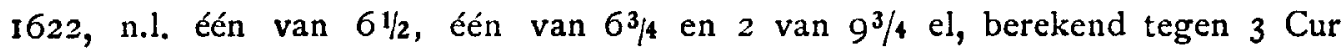
Dlr. per el.

Het heeft, zooals gezegd, als patroon "banquet op tafel". Van de vier hoofdschotels in het midden ziet men, op onze plaat, de opgemaakte ham, de haas, de pauw in de veeren, met wat ingekorten staart, en een deel slechts van een steur, terwijl de acht middensoort schaaltjes met vischjes, kreeften en vruchten zijn waar te nemen en van de acht kleine schaaltjes en bordjes, die met mesjes en vorkjes, oesters, vruchten en bloemen het patroon vormen, er een paar ontbreken.

Aan de korte zijden sluiten zich daar tegen onmiddelijk, niet door een rand met Neptunus gescheiden, de wapens aan, waartusschen Anno I62 I en de letters K. T. Volgens Mejuffrouw MYGDAL zijn de omringende wapens, behalve het rijks wapen, reeds in Oud Holland vermeld: Gullands lam met vaan, IJslands stokviscin, ølands arend en Telmerns kroon.

De afhangende rand is over de geheele lengte, afgescheiden door een smallen rand van vruchten en bladeren, van onderen begrensd door een even breeden van takjes en bloemen. Aan de eene zijde is een lange-jacht van ruiters en voetknechten met hazewinden op een haas in lage landen aan den voet van duinen, waaraan een kerkje, een kasteeltje en een molentje liggen; aan de andere ziet men de zeilwagens, over het strand, langs de zee met haar schepen voor den wind zeilen. De bekende prent ${ }^{2}$ ) heeft wel invloed gehad, maar is niet slaafsch

1) Dit schijnen Deensche ellen daar de maat als 4,15 bij 2.12 opgegeven wordt.

2) Frederik MULLER, Historieplaten Ir57. 
gevolgd. Het geheel is sierlijker. Kleine bijzonderheden zijn gewijzigd. Op de vlag van den kleinen zeilwagen heeft het ingewikkelde wapen van den prins geen plaats meer kunnen vinden. Van den grooten zeilwagen hebben zoowel de kleine voorste mast, die op de prent een langen wimpel heeft, als de groote daar achter een vlag met den hollandschen leeuw. Er zijn veel minder inzittenden in de wagens. Tusschen de wagens duidt een enkele rennende ruiter met hazewind hun snelheid aan. Jammer dat onze afbeelding het Scheveningsche duin niet weer geeft, waarboven de masten der pinken uitsteken evenmin als de menschen die de zeilwagens zien vertrekken. Beide randen, vooral de jacht, gelijken in stijl op het werk van ESAIAS YAN DE VELDE.

Beiderzijds door een randje van verschillende zeehorens, dat misschien aan den rand met Neptunus herinnert, afgesloten, geven de hoeken geen „bloempotten" maar, in rijke renaissance omgeving, gevleugelde knaapjes, die mij de elementen lijken voor te stellen.

Ik heb geen afdoende reden het ontwerp van deze hoeken ook aan LAMERTijs toe te schrijven. Zij kunnen dus van Paulus JARMa von ACKeN of van Peter Heuschen, beide patroonteekenaars van de koninklijke zijdeweverij zijn, al is daar evenmin een aanwijzing voor. Want in die zijdeweverij werd dit linnendamast geweven. Het behoeft ons dus niet te verbazen het patroon ook in zijde uitgevoerd te vinden, al had men nauwelijks kunnen verwachten dat het op zou duiken in de schatkamer te Moskou, in twee exemplaren, een in roode en geele, het andere in blauwe en witte zijde geweven, een geschenk den $29^{\text {sten }}$ April I622 door ChristiaAN IV aan den gezant van Czaar MichaEl FEODOROWitch voor zijn vorst overhandigd, Fig. 2O, hier Pl. II.

$\mathrm{Zij}$ waren blijkbaar eerst voor den koning zelven bestemd geweest, want in een randje boven de wapens met het zelfde ANNo I62I en de zelfde letters $\mathrm{K} \mathrm{T}$ staat: CHRISTIANUS - 4 - VAN - GHODES - GHENADEN - FRIS en er onder: IN - ALLEN - SINE - DADEN - IS ANNO - I622. Voor het overige is alles het zelfde, behalve dat in plaats van een kriebelig figuurtje boven de tafereelen der lange randen, hier engeltjes zijn die in een krans het woord GI_ORIA houden, dat de schulpen aan de zijde van de jacht door ruitjes vervangen zijn en vooral dat in plaats van de zeilwagens een zeeslag de eene lange zijde versiert.

Hoewel de eenige vlaggen, waarvan ik de teekening kon onderscheiden, die met de drie kronen van $Z_{\text {weden }}$ zijn, en dit patroon, een overwinning der Deenen op de $Z$ weden in den oorlog van $1611-13$, wel voor den koning zal ontworpen zijn, is het zoo geheel in den geest van de beide andere randen, dat ik het gaarne ook aan LAMERTIJN zou willen toeschrijven. De stijl herinnert aan VROOM. 
Maar in het geheele uitvoerige stuk van Mejuffrouw MYGDAL kwam de naam LAMERTIJN niet voor, onder de wevers niet, met hun Hollandsche en Duitsche namen als FrandTSZ VON DER SPELL "Legatiurweffner” en JOHAN GERITZEN "Dischdechenweffver" die die tafellakens geweven hebben, Matthias Sander von Achen, Adam Adams, Christoffel Wolf, Jacob Dijckins, Abraham DE VOS, damastwevers, en niet wanneer 's konings hoedenmaker WILLOM CHARON, CARRON of GARON, inwoner, geen burger, van Kopenhagen, den koning voor eigen gebruik verkoopt I62 el fijn damasttrielje tegen 2 daalders I oort per el en voor I 78 el "serviet biliegger" tegen 3 oort ( $3 / 4$ daalder) per el, hoewel juffrouw MYGDAL het vermoeden uitspreekt dat licht sprake zou zijn van de servetten met de Deensche wapens, die zij nog niet wist dat ik aan LAMErTIJN kon toewijzen.

De overeenkomst van naam met dien van CARRON, dien wij zich in 1606 zagen belasten met den verkoop van damasten van LAMERTIJN in Engeland, heeft mij eerst doen denken dat zij gelijk had, maar die gelijkenis met NOEL DE CARRON kan toeval zijn en de prijs is toch zeker voor het werk van onzen wever veel te laag. Wanneer in 's konings rekeningen de betaling van de servetten van PASCHIER niet gevonden worden, zijn zij allicht ook een geschenk van de Staten van Holland geweest.

Zoo stonden wij'dus voor een raadsel, dat juffrouw MYGDAL die, hoewel patroonteekenares van haar ambacht, niet tegen archief-onderzoek opziet, zoo goed als geheel heeft opgelost. Voor haar toestemming om, wat zij reeds vond te mogen uitgeven, zeg ik haar gaarne mijn oprechten dank. Ik stel haar ijverige navorschingen te meer op prijs, omdat $z \mathrm{ij}$, die meende den roem van het mooiste stuk linnendamast geweven te hebben voor CHRISTIAANS zijdeweverij te mogen opeischen, zich die getroost heeft met het vooruitzicht een belangrijk aandeel in die eer aan een buitenlander te moeten afstaan.

Haar eerste onderzoek, bij beperkten tijd, bracht reeds den naam van PASCHIER Lamertijn aan het licht, zij het ook in andere verhouding dan te verwachten was.

Hij wordt niet vermeld in de lijsten in het bijzonder gemaakt voor iederen wever, waarin vermeld worden den aard van hun werk in kleur, gewicht, grootte, prijs enz., maar in de lijsten van de loonen, aan alle handswerkslieden betaald van I Mei 1620 tot 1623 , toen de zijdeweverij rechtstreeks aan den koning toebehoorde, waar staat:

PASquier Lambertin bomside weffer . . . . . $167 \mathrm{Cr} \mathrm{Dlr.}$

Dat is heel weinig in vergelijking met anderen. De reeds genoemde JoHAN Geritzen kreeg 933 Cr Dlr 2 zs $4 \beta$, zijn medewerker Frans yon DER SPELL 200-2-9, de damastwevers Jaсов Dijkinn i $38 \mathrm{I}-3-6$, MatThias Sannders 


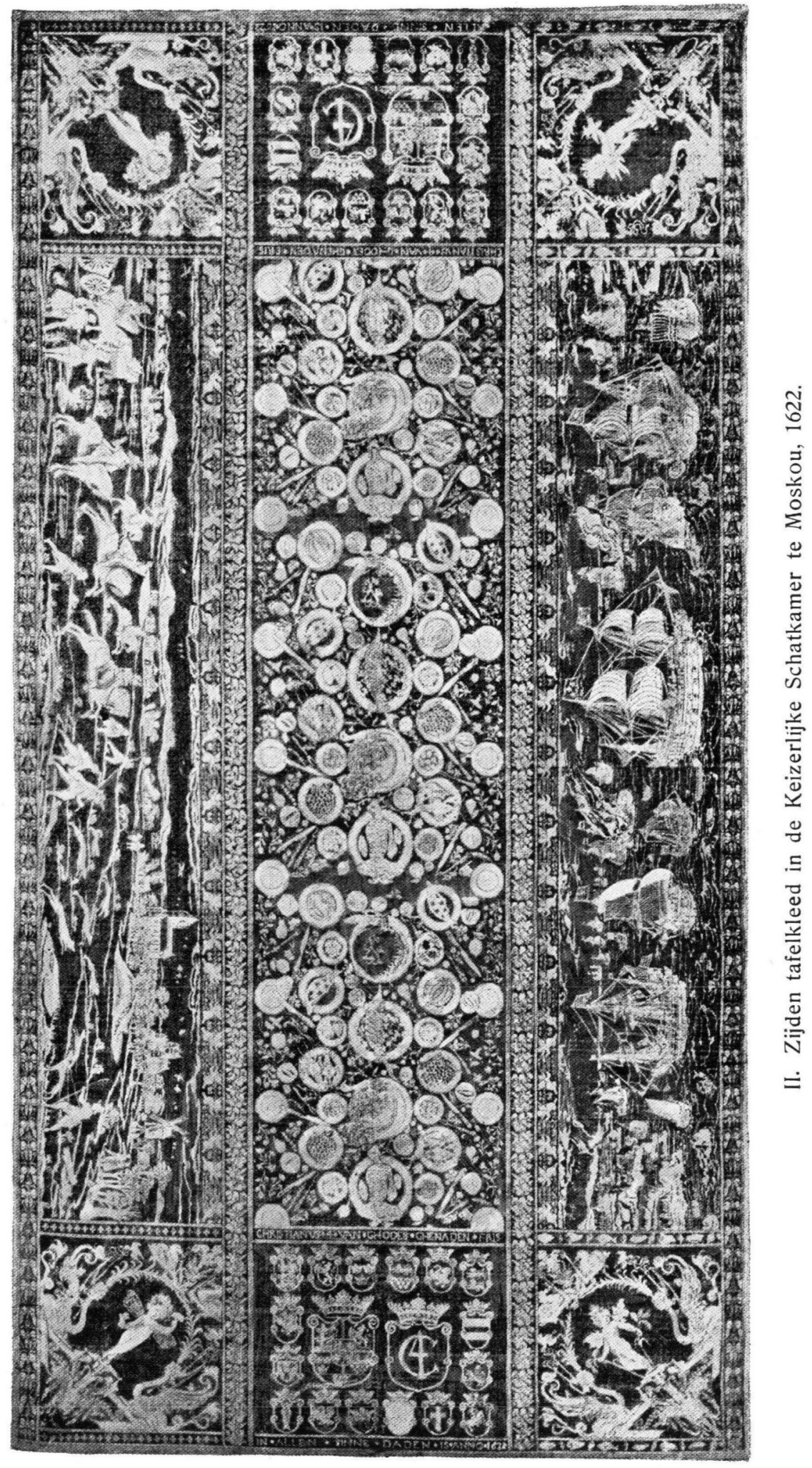



HET EINDE VAN PASCHIER LAMERTIJN.

von Achen 833-2-6, Adam Adams 725-2-81/2 en Christoffel WolfF $48 \mathrm{I}-\mathrm{I}-\mathrm{I} 7$.

Ook in een lijst van grondstoffen aan de wevers verstrekt, komt hij met een luttel bedrag voor. Hij staat aldus te boek:

Pasquier Lambertinn linen . . . . . 9 ph. Pp.

Sedert vond zij omtrent dezelfde posten een nog belangrijker aanteekening:

Pasquier Lambertinn, Bomside Weffner.

Tra dennd 4 Augusti Anno I620; Hannom forst ehr bleffnen betallet till dend 24 Novembri Anno I62 I : hannd werd Dòden ehr affgangen.

Bekommidt

Penninger . . . . . . . . I67 Cr D.

Danndziger Linengarn .. . . . . 9 Schok.

Nota. Disse 9 Schok garnn findes iche i Carel. Thiessens bóger hannom adt werre tillreignedt menns hanns Weffne æds als tillbetior, Kong Morett: efter hanns dòd emod huis haand er schyldig bleffen adt werre tillreignedt.

Dat is :

Pasquier Lambertinn, Boomzijdewever.

Van den $4^{\text {den }}$ Augustus Anno 1620, waarop hij het eerst werd betaald, tot den $24^{\text {sten }}$ November Anno 162 I toen hij door den dood is heengegaan.

Heeft gekregen: in penningen . . . . . . . $167 \mathrm{Cr} \mathrm{D}$.

Dantziger linnengaren ....... 9 Schok.

Nota. Deze 9 schok linnen worden niet gevonden in de boeken van CARELL ThIESSEns als hem toegerekend. Derhalve moeten zijn getouw en al zijn werktuigen $Z$. M. den Koning toegerekend worden als betaling van zijn schulden.

Danziger linnen plagt, zooals weer Mejuffrouw MYGDAL mij mededeelde, te Kopenhagen, in tegenstelling met ander dat bij het pond ging, per schok gerekend te worden. I Schok van 60 Stück van 20 Gebinde van 40 Faden van $3^{1 / 2}$ ellen (2.3342 M.) is I 2000 M. dus 9 Schok I.008.00o M. zeker een niet onbelangrijke waarde vertegenwoordigend, maar toch niet meer dan om 210 el $4 / 4$ van 24 hondert fijnte of 168 van 3000 fijnte te weven en dus nauwlijks genoeg voor de inbeslagname van zijn geheele getouw en al zijn instrumenten, waaronder zijn patronen wel zullen geweest $z i j n$, te verklaren, lijkt het mij.

Met het oog op zijn vroegere pogingen om zijn weef kunst naar Engeland, en naar Frankrijk over te brengen en lettend op wat wij over zijn vestiging te Alkmaar weten, zou ik willen gissen, dat hij geld van den Deenschen koning had geleend, toen hij dezen er toe wist te brengen onder eigen beheer in 1619 
de Kong Masdet Nederlandske Manufactur og Silkework op te richten en volgens de plannen van HANS STENWINKEL 14 huizen van twee verdiepingen te bouwen voor wevers, die I Mei 1620 hun eerste werk inleverden.

Deze weverij, waar dus ook zijde geweven werd, stond onder toezicht van Carell Thiessen. Het kan de bedoeling zijn geweest dat Paschier een niet onbelangrijk aandeel in de inrichting zou nemen. Misschien heeft reeds spoedig ziekte hem belet dit te doen. Nog bij zijn leven schijnen zijn patronen door anderen uitgevoerd te zijn.

Voor 1619 is hij niet in Denemarken geweest, want zooals uit de bijlagen blijkt, die ik tijdens de correctie van den Heer BREDIUs mocht ontvangen, is hij nog in dat jaar te Amsterdam, voornemens weder te gaan weven, terwijl hij in de voorafgaande jaren, sedert 1616 dus waarschijnlijk, in Frankrijk en Engeland zijn weefsels aan koningen en groote heeren heeft afgezet.

ChristiaAN IV die zijn werk kende, schijnt op zijn advertentie te zijn ingegaan.

Geboren, blijkens de vroeger vermelde akte en een verklaring van 22 Juli I608 1) tusschen 3 Februari en 22 Juli 1562, was hij bij zijn overlijden 59 jaar oud.

Eenigzins verrassend is het zeker hem in de aangehaalde stukken tweemaal als bomsideweffner vermeld te vinden. Bomside is geen Deensch woord. Het kan niet anders zijn dan het Hollandsche boomzijde, dat blijkens het Nederlandsch Woordenboek voor bombazijn gebruikt werd. Bombazijn is, al is het later ook wel van andere stoffen gemaakt, oorspronkelijk een bijzondere soort zijden weefsel, waarop ook reeds de naam, een verbastering van bombycina, wijst. In 1597 zagen wij dat PASCHIER zaken deed met CAREL LODEwIJKSZ VAN DER HELST in grogreynen. Was hij dan soms een wever van alle markten thuis? Heeft hij misschien te Kopenhagen de damastweefsels aan zijn leerlingen overgelaten ten einde zelf bombazijn te weven, omdat niemand dat kon of wellicht omdat het minder zwaar werk was.

Hoe dit zij, het blijkt in elk geval dat zijn uitvinding van een bijzondere kunst van damastweven, te Haarlem gedaan, waar hij reeds in 1586 woonde, ${ }^{2}$ )

1) Not. E. VAN Bosvelt te Haarlem: D'eersame PASSchier Lammertijn, inwonende binnen der stede van Alcmaar oud 46 jaren. Hij teekent Passchier Lamartis.

2) 9 Juli 1586 legt hij met twee andere coopluyden in Ammelaecken een verklaring af voor Not. M. VAN WAERDEN, fol, 282, te Haarlem. Mei r591 woonde hij daar Lange Bagyenestraat in 't huys van ADRIAEN VAN DUVELANDE, 25 Jan. 1592 in de Groote Houtstraat in 't huis van Willem Stuver naast de Granaatappel 23 November 593 maakt Hans Lammertijn van Cortrijck zijn testament bij Not. A. WiLlems, fol. I23 vs., te Haarlem en vermaakt zijn broeder PAsSCHIE 3 gld. Van 3 I Aug. 1613 is een insinuatie bij Not. G. v. D. Gheest te Alkmaar fol. 80, van Passchier Lambertijn aan Cornelis Jassz Kelderman omtrent de verbeteringen van servetten en den koop van twee amela eckens waarvoor ruim 20 gulden geboden is. (Mededeeling van den Heer vaN ZUIDEN).

Ook JACQUes LAMMERTij, damastwerker van Cortrijck, die reeds in 1599 bij Not. A. WiLLEmSz, 
en die hem te Alkmaar beroemd maakte, naar Kopenhagen werd overgebracht en hij zelf daar zijn einde vond.

Waarschijnlijk overleefde ook zijn kunst hem daar niet lang. De zijdeweverij van den koning werd 30 November 1623 overgedragen aan een compagnie, die zich evenwel niet bedruipen kon, niettegenstaande de koning al het mogelijke deed om te steunen en zelf voor 40.000 Cur. dlr. aan waren overnam.

Het mag haast een wonder heeten dat toch nog zooveel is overgebleven van LAMERTIJNS werk dat wij er een voldoende voorstelling van kunnen krijgen.

voorkomt, die in r604 Jacop Lammertin PAsschierszone genoemd wordt en 5 Januari 1605 bij Not. voN Trier Jaqus Lammartijn als als getuige teekent, is de zoon van onzen Paschier blijkens een insinuatie van 9 April 1609 bij Notaris G. VAN DER GheEst, te Alkmaar, van PAsschier Lambfrtijn als vader van JaCques Passchiers tegea Susanna Willemszdr. die ten onrechte bewpert bad, dat Jacques de vader van haar kind was.

29 Aug. 1652 vinden wij nog te Haarlem, in de Rollen, een Pieter Passchiers, die iemand een stuk „Doornicx Damast" levert en een wevers treckkam heeft laten maken.

Verder komt nog 6 April 1663 te Amsterdam bij Not. Hellerus een Hendrick Lammertijn, oud 32 jaar als damastwercker voor die een kleinzoon van PASCHIER en een zoon van een vroeger (O. H. 19I3 blz. IOr) vermelden Pieter PAsschiers zou kunnen zin.

Al deze gegevens uit notarieele stukken hebik weer aan de vriendelijkheid van den Heer BREdus te danken. 